\title{
Original
}

\section{Surgical treatment of tertiary hyperparathyroidism after renal transplantation: A 31-year experience in a single institution}

\author{
Jae Hyun Park, Sang-Wook Kang, Jong Ju Jeong, Kee-Hyun Nam, Hang Seok Chang, Woong Youn Chung \\ and Cheong Soo Park
}

Department of Surgery, Yonsei University College of Medicine, Seoul 120-752, South Korea

\begin{abstract}
Tertiary hyperparathyroidism (tHPT) most commonly refers to a persistent secondary hyperparathyroidism even after successful renal transplantation. Parathyroidectomy (PTX) is an efficient method for treatment of tHPT. In this study, we examined our 31-year experience with patients who underwent PTX for tHPT after KTX and assessed the effects of PTX on graft function according to the type of surgery. Among 2,981 recipients who underwent renal allograft between April 1979 and Dec. 2010, 15 patients (0.5\%) were identified as having tHPT and underwent PTX. Levels of intact parathyroid hormone (iPTH) and serum calcium were measured before and after PTX for evaluation of the therapeutic effect, and glomerular filtration rate (GFR) using the Modification of Diet in Renal Disease (MDRD) equation for investigation of any effect on graft function. One patient showed persistent hyperparathyroidism and hypercalcemia after limited PTX. We experienced 14 successful PTXs, including 3 total PTX with autotransplantations, 8 subtotal PTXs, and 3 limited PTXs. Levels of iPTH and serum calcium were at normal range after PTX. Estimated GFR decreased after PTX. Total PTX with autotransplantation showed a tendency of more decrease in the values of iPTH, and GFR after PTX than Subtotal PTX. PTX can cure tHPT-specific symptoms and signs by recovery of hypercalcemia, but may carry the risk of deterioration of kidney graft function. We suspect that subtotal PTX, rather than total PTX with AT, prevent any risk of kidney graft deterioration in surgical treatment of tHPT, and, in selective tHPT patients, limited PTX might be recommended.
\end{abstract}

Key words: Tertiary hyperparathyroidism, Parathyroidectomy, Renal transplantation

TERTIARY hyperparathyroidism (tHPT) can develop after any long-standing period of hypocalcemia, such as those seen with chronic dialysis or gastrointestinal malabsorption; however, tHPT occurs most commonly in the setting of kidney transplantation (KTX), whereby patients with secondary HPT continue to have elevated parathyroid hormone (PTH) levels after KTX. tHPT has been reported in up to $50 \%$ of patients who underwent KTX [1, 2] and its occurrence is thought to be related to severity of pretransplant HPT [3] and duration of dialysis prior to transplantation $[1,4,5]$.

Submitted May 27, 2011; Accepted Jul. 15, 2011 as EJ11-0053 Released online in J-STAGE as advance publication Jul. 30, 2011

Correspondence to: Jong Ju Jeong, M.D., Department of Surgery, Yonsei University College of Medicine, C.P.O. Box 8044, 250 Seongsanno, Seodaemun-gu, Seoul 120-752, South Korea E-mail: jungjongj@yuhs.ac

Sources of financial support: The authors have no conflict of interest to declare.
tHPT can cause serious problems, including hypercalcaemia, osteitis fibrosa cystica, osteoporosis leading to increased risk of fracture, soft tissue calcification, bone pain, myopathy with muscular weakness, tendon rupture, anaemia (refractory to erythropoietin), arterial hypertension, and hypercalciuria that increases the risk of kidney stone disease, which is particularly deleterious in a renal graft [4, 6-12].

tHPT has been recognized for a long time; however, management of the disease remains controversial. Currently, patients with persistent hypercalcemia of one year or more after KTX should be considered for PTX. However, surgery for tHPT within the first year should be considered only if medical treatment fails to control morbidity.

Surgical treatment for tHPT has been either total parathyroidectomy with autotransplantation (total PTX + AT) $[9,13,14]$ or subtotal PTX [15-17]. Limited glandular resection has recently been advocated in 
patients presenting with only one or two macroscopically enlarged glands $[18,19]$. However, surgical consensus on the optimal procedure has not been reached. Despite previous reports showing that patients with functioning kidney grafts had unaffected renal function after PTX, according to recent reports, PTX might seriously endanger long-term graft survival [20-22].

The purpose of this study was to examine our 31-year experience with patients who underwent PTX for tHPT after KTX and to assess the effects of PTX on graft function according to the type of surgery.

\section{Patients and Methods}

Between January 1979 and December 2010, 2981 patients underwent KTX in Severance Hospital, Yonsei University College of Medicine. Of these, 15 patients (0.5\%) who underwent PTX were included in the study. All patients were diagnosed previously with secondary hyperparathyroidism, and had severe hypercalcemia (more than $11.5 \mathrm{mg} / \mathrm{dL}$ ) jeopardizing the kidney transplant within the first year after KTX, persisting asymptomatic hypercalcemia (more than one year after KTX), or symptomatic tHPT (nephrocalcinosis or stone formation of the renal graft, severe renal osteopathy, soft tissue calcification, muscle or bone pain, or pruritus at any time after KTX).

Preoperative localization studies were performed in all patients. Patients who had a single adenoma suspected strongly in preoperative localization studies underwent limited PTX, and patients with multiple gland disease or failure to preoperative localization underwent total PTX + AT or subtotal PTX. Simultaneous thymectomy had not performed in all patients.

At the time of surgery for tHPT, normal functioning of the graft kidney was identified. For immunosuppression, calcineurin inhibitors and steroids were utilized in all patients. Cyclosporine levels were checked regularly in each patient. Immunosuppressive medication was not altered or withdrawn in any patient within the perioperative period, at least one year.

Data collected and evaluated included patient demographics, type and duration of dialysis, interval between KTX and PTX, radiological studies, type of operation, pathology of the parathyroid glands, postoperative complications, and outcome. Adenomas were defined based on the presence of a compressed rim of normal appearing parathyroid tissue in the involved gland and normal or atrophic parathyroid tissue in the uninvolved glands. ${ }^{18}$ Hyperplasia (nodular or diffuse) was diagnosed that as the number of parathyroid parenchymal cells proliferated, they formed lobular structures (diffuse hyperplasia), and the glands exhibited at least one well-circumscribed, encapsulated nodule (nodular hyperplasia). The outcome used for measurement of success or failure after PTX was persistent or recurrent hypercalcemia and increased serum iPTH levels.

For assay of the effects of PTX on tHPT and on graft function, iPTH, total serum calcium $(\mathrm{Ca})$, and GFR were observed on preoperative day one, postoperative day 3, and at 3 months, 6 months, and 12 months in successful patients after PTX. In addition, for assay of the effects on graft function according to surgical method, difference of iPTH, total serum Ca, and GFR between pre- and postoperative were calculated using each postoperative value minus that of preoperative day one. PTH levels were measured using an intact PTH assay, measured by a standard radioimmunometric assay (Nichols Institute, San Clemente, CA, USA; reference range, $10-60 \mathrm{pg} / \mathrm{mL}$ ). The Modification of Diet in Renal Disease (MDRD) equation was used for calculation of the GFR. Persistent or recurrent disease was defined as hypercalcemia (serum $\mathrm{Ca}$ concentration $>10.5 \mathrm{mg} / \mathrm{dL}(2.62 \mathrm{mmol} / \mathrm{L})$ and iPTH level above the reference range during the first 6 months after PTX (persistent) or thereafter (recurrent).

Institutional Review Board approval was obtained for this investigation. All statistical analyses were performed using SAS 9.1.3 (Cary, NC), and $P$ values $<0.05$ were considered statistically significant. Comparisons between preoperative and postoperative $\mathrm{iPTH}$, total serum $\mathrm{Ca}$, and GFR levels were made with mixed analysis or Friedman test. Comparisons among surgical methods were made with GLM and Bonferroni adjustment.

\section{Results}

Of fifteen consecutive patients ( 7 females, 8 males) who underwent PTX for tHPT after KTX, mean age at PTX was 45.6 years (range 34 56). Duration of hemodialysis prior to KTX was 117.7 months (range 27 204) and the time from KTX to PTX was 43.3 months (range, 5 124). Patients were followed up for a median of 54 months (range 23 142) (Table 1).

Thirteen patients had persisting hypercalcemia more than one year after KTX, and, of these, 7 patients (46.7\%) were asymptomatic and $6(40.0 \%)$ patients were symptomatic tHPT. Two patients (13.3\%) underwent PTX 
Table 1 Clinicopathological features fo patients

\begin{tabular}{|c|c|c|c|c|c|c|c|c|}
\hline Sex/Age & $\begin{array}{l}\text { Duration of } \\
\text { HD (month) }\end{array}$ & $\begin{array}{c}\text { Interval between } \\
\text { PTX \& KTX (month) }\end{array}$ & Symptoms & $\begin{array}{l}\text { Localization } \\
\text { study }\end{array}$ & Operation & Pathology & $\begin{array}{l}\text { Postoperative } \\
\text { complication }\end{array}$ & Outcome \\
\hline $55 / \mathrm{M}$ & 204 & 12 & & $\mathrm{Mibi}+\mathrm{U} / \mathrm{S}+\mathrm{CT}$ & Subtotal & $\mathrm{DH}$ & & Success \\
\hline $50 / \mathrm{F}$ & 96 & 16 & & $\mathrm{Mibi}+\mathrm{U} / \mathrm{S}+\mathrm{CT}$ & Subtotal & $\mathrm{DH}$ & & Success \\
\hline $34 / F$ & 108 & 18 & & $\mathrm{Mibi}+\mathrm{U} / \mathrm{S}$ & Subtotal & $\mathrm{DH}$ & & Success \\
\hline $42 / \mathrm{F}$ & 156 & 24 & agitation & $\mathrm{Mibi}+\mathrm{U} / \mathrm{S}+\mathrm{CT}$ & Total+AT & DH & & Success \\
\hline $50 / \mathrm{F}$ & 117 & 28 & & $\mathrm{Mibi}+\mathrm{U} / \mathrm{S}$ & Limited & Adenoma & & Success \\
\hline 49/M & 160 & 87 & arthralgia & $\mathrm{Mibi}+\mathrm{U} / \mathrm{S}$ & Subtotal & DH & & Success \\
\hline $49 / \mathrm{F}$ & 134 & 28 & & $\mathrm{Mibi}+\mathrm{U} / \mathrm{S}$ & Total + AT & $\mathrm{DH}$ & $\mathrm{TH}$ & Success \\
\hline $47 / \mathrm{M}$ & 108 & 13 & & $\mathrm{Mibi}+\mathrm{U} / \mathrm{S}$ & Subtotal & DH & & Success \\
\hline $56 / \mathrm{F}$ & 154 & 5 & & Mibi & Limited & Adenoma & $\mathrm{TH}$ & Success \\
\hline $39 / \mathrm{M}$ & 60 & 6 & arthralgia & $\mathrm{Mibi}+\mathrm{U} / \mathrm{S}$ & Total+AT & ND & & Success \\
\hline $38 / \mathrm{M}$ & 192 & 50 & myalgia & $\mathrm{Mibi}+\mathrm{U} / \mathrm{S}$ & Subtotal & $\mathrm{DH}$ & & Success \\
\hline $50 / \mathrm{M}$ & 27 & 30 & & $\mathrm{Mibi}+\mathrm{U} / \mathrm{S}+\mathrm{MRI}$ & Limited & Adenoma & & Success \\
\hline $42 / \mathrm{F}$ & 96 & 122 & palpitation & $\mathrm{Mibi}+\mathrm{U} / \mathrm{S}$ & Subtotal & $\mathrm{DH}$ & $\mathrm{TH}$ & Success \\
\hline $42 / \mathrm{M}$ & 72 & 89 & myalgia & $\mathrm{Mibi}+\mathrm{CT}$ & Subtotal & $\mathrm{DH}$ & $\mathrm{TH}$ & Success \\
\hline 41/M & 82 & 124 & arthralgia & $\mathrm{Mibi}+\mathrm{U} / \mathrm{S}$ & Limited & DH & & Failure \\
\hline
\end{tabular}

HD, hemodialysis; PTX, parathyroidectomy; KTX, kidney transplantation; Mibi, ${ }^{99 m}$ Tc-sestimibi scintigraphy; U/S, ultrasonography; CT, computed tomography; MRI, magnetic resonance imaging; Total+AT, total parathyroidectomy with autotransplantation; Subtotal, subtotal PTX; Limited, limited PTX; DH, diffuse hyperplasia; ND, nodular hyperplasia; TH, transient hypocalcemia

within the first year after KTX (Table 1). One did not show a significant change of iPTH level during the sixth month after KTX $(856 \rightarrow 826 \mathrm{pg} / \mathrm{mL})$, and had severe hypercalcemia $(13.1 \mathrm{mg} / \mathrm{dL})$ with symptoms. Another showed an increased iPTH level during the fifth month after KTX $(217 \rightarrow 225 \mathrm{pg} / \mathrm{mL})$ and had severe hypercalcemia $(11.8 \mathrm{mg} / \mathrm{dL})$ without symptoms.

Preoperative localization studies were performed in all patients. Nine patients underwent ${ }^{99 \mathrm{~m}}$ Tc-sestimibi scintigraphy and ultrasound. Four patients underwent ${ }^{99 m}$ Tc-sestimibi scintigraphy, ultrasound, and neck computed tomography (CT) or magnetic resonance imaging (MRI). Two patients underwent ${ }^{99 \mathrm{~m}}$ Tc-sestimibi scintigraphy only, or ${ }^{99 \mathrm{~m}}$ Tc-sestimibi scintigraphy and neck CT (Table 1).

Eight patients underwent a subtotal PTX and 3 patients underwent a total PTX + AT for tHPT. Four patients who had a single adenoma suspected strongly in preoperative localization studies underwent limited PTX. According to microscopic examination, eleven patients had diffuse hyperplastic glands, three patients had a single adenoma, and one patient had nodular hyperplastic glands. There were no postoperative deaths. Four patients $(26.7 \%)$ had transient hypocalcemia as a perioperative complication but they were eucalcemic without the calcium replacement in the first
6 months after PTX, and there were no other perioperative complications. Fourteen patients underwent successful PTXs in which levels of iPTH and serum calcium were at normal range after PTX, and one patient who had undergone limited PTX showed persistent hypercalcemia and underwent subtotal PTX at the thirteenth month after the first operation (Table 1). During a median follow-up period of 54 months (range 23 142), there was no occurrence of PTX-related deterioration of kidney graft function.

Preoperative and postoperative day 3, 3 month, 6 month, and 12 month iPTH levels in patients $(\mathrm{n}=14)$ who underwent successful PTXs were 248.8 \pm 192.4 , $15.2 \pm 13.9,44.2 \pm 18.1,38.1 \pm 22.9$, and $35.3 \pm 17.2$ (pg/ $\mathrm{mL}$ ), respectively. Total serum calcium levels were $11.5 \pm 0.9,8.9 \pm 1.0,9.4 \pm 0.8,9.3 \pm 0.9$, and $9.4 \pm 0.6$ (mg/ $\mathrm{dL}$ ), respectively. iPTH level and total serum calcium showed a decline into the normal range after PTX and showed a significant decline on postoperative day 3 . A significant difference in iPTH level and total serum calcium was observed between preoperative and postoperative day 3, 3 month, 6 month, and 12 month $(p<0.01)$. Estimated GFR using the MDRD equation were $65.3 \pm 14.7,63.6 \pm 16.4,66.6 \pm 17.3,63.7 \pm 17.5$, and $62.3 \pm 16.2\left(\mathrm{~mL} / \mathrm{min} / 1.73 \mathrm{~m}^{2}\right)$, respectively. With passage of time, estimated GFR showed a slight decrease; 
Table 2 Preoperative versus postoperative laboratory values

\begin{tabular}{|c|c|c|c|c|c|c|}
\hline & PTH (pg/mL) & $p$ value & Serum Calcium (mg/dL) & $p$ value & $\operatorname{GFR}\left(\mathrm{mL} / \mathrm{min} / 1.73 \mathrm{~m}^{2}\right)$ & $p$ value \\
\hline Preoperative day 1 & $248.8 \pm 192.4$ & $<0.01$ & $11.5 \pm 0.9$ & $<0.01$ & $65.3 \pm 14.7$ & 0.55 \\
\hline Postoperative day 3 & $15.2 \pm 13.9$ & & $8.9 \pm 1.0$ & & $63.6 \pm 16.4$ & \\
\hline Postoperative 3 month & $44.2 \pm 18.1$ & & $9.4 \pm 0.8$ & & $66.6 \pm 17.3$ & \\
\hline Postoperative 6 month & $38.1 \pm 22.9$ & & $9.3 \pm 0.9$ & & $63.7 \pm 17.5$ & \\
\hline Postoperative 12 month & $35.3 \pm 17.2$ & & $9.4 \pm 0.6$ & & $62.3 \pm 16.2$ & \\
\hline
\end{tabular}

Table 3 Difference between preoperative and follow-up iPTH according to surgical method (pg/mL)

\begin{tabular}{lcccc}
\hline & Total + AT & Subtotal & Limited & $p$ value \\
\hline Postoperative day 3 & $-426.7 \pm 351.0$ & $-185.1 \pm 122.0$ & $-169.8 \pm 65.5$ & 0.85 \\
Postoperative 3 month & $-402.4 \pm 370.4$ & $-158.1 \pm 133.9$ & $-137.1 \pm 69.1$ & 0.74 \\
Postoperative 6 month & $-404.6 \pm 361.3$ & $-147.2 \pm 121.6$ & $-137.3 \pm 52.4$ & 0.74 \\
Postoperative 12 month & $-212.9 \pm 97.5$ & $-166.7 \pm 114.5$ & $-146.2 \pm 54.3$ & 0.5 \\
\hline
\end{tabular}

Table 4 Difference between preoperative and follow-up serum calcium according to surgical method (mg/dL)

\begin{tabular}{lcccc}
\hline & Total + AT & Subtotal & Limited & $p$ value \\
\hline Postoperative day 3 & $-3.9 \pm 1.9$ & $-2.3 \pm 1.2$ & $-2.1 \pm 2.0$ & 0.28 \\
Postoperative 3 month & $-3.7 \pm 1.5$ & $-2.0 \pm 1.0$ & $-1.2 \pm 0.7$ & 0.04 \\
Postoperative 6 month & $-3.8 \pm 1.6$ & $-1.6 \pm 0.9$ & $-1.8 \pm 1.1$ & 0.05 \\
Postoperative 12 month & $-2.8 \pm 1.7$ & $-2.0 \pm 0.9$ & $-1.9 \pm 1.5$ & 0.56 \\
\hline
\end{tabular}

Table 5 Difference between preoperative and follow-up GFR according to surgical method $\left(\mathrm{mL} / \mathrm{min} / 1.73 \mathrm{~m}^{2}\right)$

\begin{tabular}{lcccc}
\hline & Total + AT & Subtotal & Limited & $p$ value \\
\hline Postoperative day 3 & $-4.7 \pm 8.1$ & $-0.4 \pm 4.6$ & $-2.1 \pm 3.4$ & 0.5 \\
Postoperative 3 month & $-2.5 \pm 12.7$ & $1.3 \pm 7.6$ & $5.2 \pm 9.3$ & 0.59 \\
Postoperative 6 month & $-10.2 \pm 6.6$ & $0.1 \pm 4.6$ & $3.4 \pm 14.0$ & 0.11 \\
Postoperative 12 month & $-11.8 \pm 2.1$ & $0.3 \pm 10.2$ & $2.1 \pm 9.7$ & 0.27 \\
\hline
\end{tabular}

however, no significant decrease was observed between preoperative and postoperative $(p=0.55)$ (Table 2 ).

Difference of iPTH between preoperative and postoperative day 3, 3 month, 6 month, and 12 month according to surgical method declined more in order of total PTX with AT, subtotal PTX, and limited PTX; however, with passage of time, difference of iPTH according to surgical method decreased. There was no significant difference among surgical methods (Table 3). Difference of total serum calcium according to surgical method declined more in order of total PTX with
AT, subtotal PTX, and limited PTX, too. A significant difference was observed according to surgical method between preoperative and postoperative 3 month and 6 month ( $p=0.04,0.05$ ); however, with passage of time, difference of total serum calcium according to surgical method decreased (Table 4). Estimated GFR, with passage of time, decreased more and more after total PTX with AT, but, rather, increased from postoperative month 3 in subtotal PTX and limited PTX. No significant difference was observed among surgical methods (Table 5). 


\section{Discussion}

Chronic renal failure leads to retention of phosphorus and deficient production of 1,25-hydroxyvitamin D. This results in a decreased serum calcium level, providing a strong and persistent stimulus to the parathyroid glands, and leads to secondary HPT. In general, in most patients with secondary HPT, hypercalcemia shows gradual resolution within the first year after successful KTX due to normalization of stimuli $[4,5]$. However, in patients with tHPT, restoration of normal renal function following successful KTX fails to result in normalized secretion of PTH, which has become autonomous and inappropriate with respect to calcium and calcitriol levels.

Management of patients with tHPT is predominantly surgical, whereas treatment of patients with secondary HPT is medical. Therefore, in contrast to patients with secondary HPT, patients with tHPT are not routinely given oral calcium and phosphate binders because they are typically normocalcemic or hypercalcemic and concurrently hypophosphatemic. Vitamin D (calcitriol) supplementation can be prescribed, but often only delays surgical intervention because patients typically become refractory to vitamin D replacement. Supplementation of phosphate levels with oral agents can lead to nephrocalcinosis and hyperphosphaturia, and should be administered sparingly [23].

Development of tHPT requiring surgical intervention occurs in $0.6 \%$ to $5.6 \%$ of patients with HPT after KTX [9, 24, 25]. Despite a current lack of evidencebased guidelines, PTX after KTX is recommended for patients with severe hypercalcemia (serum calcium $>11.5$ or $12 \mathrm{mg} / \mathrm{dL}$ ), persistent hypercalcemia (serum calcium $>10.2 \mathrm{mg} / \mathrm{dL}$ more than 3 months to 1 year after surgery), severe osteopenia (low bone mineral density), or symptomatic HPT [23]. In our study, most patients $(86.7 \%)$ had persistent hypercalcemia more than 1 year after KTX, and patients who underwent PTX within the first year after KTX (13.3\%) had severe hypercalcemia (serum calcium $>11.5$ ) with or without symptoms.

In several reviews, many that included long-term follow-up, more than $94 \%$ of patients with tHPT achieved biochemical cure on the basis of total serum calcium levels after PTX [18, 26-28]. In addition, improvement of symptoms has been reported in more than $90 \%$ of patients with tHPT treated with PTX [18, 27]. However, in a series of 37 patients, Schmidt et al. [21] observed an increased rate of acute rejection following PTX for tHPT. Lee et al. [22] described a negative effect of subtotal PTX on graft function in 22 patients after kidney transplantation. Garcia et al. [29] reported persistent impairment of renal function after PTX in patients who already had preoperative elevation of s-creatinine-levels. In this study, level of iPTH and serum calcium in all patients who underwent successful PTXs stayed within normal range after PTX during a median follow-up period of 54 months (range 23 142), and there was no PTX-related deterioration of kidney graft function. We thought that the latter result was due to the fact that all patients showed normal functioning of the graft kidney at the time of surgery for tHPT.

However, we found the possibility of deterioration of graft function according to surgical method. Patients who underwent total PTX with AT showed a significant decrease in the level of iPTH and serum calcium, and developed an accelerated decline in GFR after PTX. In contrast, patients who underwent subtotal PTX or limited PTX showed a decrease, less than total PTX with AT, in the level of iPTH and serum calcium, and they showed an increase in GFR from postoperative 3 months after PTX, although there was no statistically significant difference of GFR according to surgical method. Schwarz et al. [20] demonstrated that a change in PTH concentration is an important factor influencing subsequent renal function. They found a direct correlation between delta PTH decline in percent after parathyroid surgery and decline in creatinine clearance. In addition, Schlosser et al. [30] reported that the surgical technique itself has a direct impact on postoperative graft function. These data were confirmed by results from our study.

Kidney function declines after KTX, in keeping with the natural history of KTX, in which about 20\% of living patients require dialysis again 5 years after receiving a transplant [31] and about $14 \%$ experience a $\geq 20 \%$ decline in kidney function each year between the first and the fourth year after KTX, [32] and surgeons should keep in mind that renal function will decline over time in most kidney transplant recipients, leading to an increased risk of recurrent tHPT, especially patients who underwent limited PTX.

Our study is limited by its retrospective nature. In addition, due to the relatively small sample size, the possibility of alpha error cannot be ruled out. The results of this study indicate that PTX can cure tHPT 
specific symptoms and signs by recovery of hypercalcemia. However, graft-kidney function before PTX must be checked because PTX may carry the risk of deterioration of graft function. Based on its laboratory findings, we suspect that subtotal PTX, rather than total PTX with AT, prevent any risk of kidney graft deterioration in surgical treatment of tHPT, and in seletive tHPT patients, as the lesion is clearly in 1 or 2 glands, limited PTX might be recommended. Randomized controlled study with a longer follow-up period or multicenter collaborative study is necessary to create the consensus optimal procedure and guidelines in surgical management of tHPT patients.

\section{References}

1. Apaydin S, Sariyar M, Erek E, Ataman R, Yiğitbaș R, Hamzaoğlu I, Serdengeçti K, Ulkü U (1999) Hypercalcemia and hyperparathyroidism after renal transplantation. Nephron 81: 364-365.

2. McCarron DA, Lenfesty B, Thier A, Vetto M, Barry J, Krutzik S, Bennett WM (1980) Total parathyroidectomy for post-transplantation hyperparathyroidism. Proc Clin Dial Transplant Forum 10: 51-55.

3. Torres A, Lorenzo V, Salido E (2002) Calcium metabolism and skeletal problems after transplantation. $J$ Am Soc Nephrol 13: 551-558.

4. D'Alessandro AM, Melzer JS, Pirsch JD, Sollinger HW, Kalayoglu M, Vernon WB, Belzer FO, Starling JR (1989) Tertiary hyperparathyroidism after renal transplantation: operative indications. Surgery 106: 10491055.

5. Pletka PG, Strom TB, Hampers CL, Griffiths H, Wilson RE, Bernstein DS, Sherwood LM, Merrill JP. (1976) Secondary hyperparathyroidism in human kidney transplant recipients. Nephron 17: 371-381.

6. Dotzenrath C, Goretzki PE, Röher HD (1993) Renal hyperparathyroidism following kidney transplantation. Ann Ital Chir 64: 381-384.

7. Dotzenrath C, Goretzki PE, Röher HD (1993) Surgical therapy of secondary hyperparathyroidism after kidney transplantation. Langenbecks Arch Chir 378: 121-124. (In German)

8. Schlosser K, Zielke A, Rothmund M (2004) Medical and surgical treatment for secondary and tertiary hyperparathyroidism. Scand J Surg 93: 288-297.

9. Kerby JD, Rue LW, Blair H, Hudson S, Sellers MT, Diethelm AG. (1998) Operative treatment of tertiary hyperparathyroidism: a single-center experience. Ann Surg 227: 878-886.

10. Sitges-Serra A, Esteller E, Ricart MJ, Caralps A. (1984) Indications and late results of subtotal parathyroidectomy for hyperparathyroidism after renal transplantation. World J Surg 8: 534-539.

11. Sitges-Serra A, Gores P, Hesse U, Fryd DS, Najarian JS, Sutherland DE. (1986) Serum calcium as an early indicator for surgical treatment of hyperparathyroidism after renal transplantation. World J Surg 10: 661-667.

12. Triponez F, Dosseh D, Hazzan M, Noel C, Vanhille
P, Proye CA. (2005) Subtotal parathyroidectomy with thymectomy for autonomous hyperparathyroidism after renal transplantation. Br J Surg 92: 1282-1287.

13. Wells SA Jr, Gunnells JC, Shelburne JD, Schneider AB, Sherwood LM. (1975) Transplantation of the parathyroid glands in man: clinical indications and results. Surgery 78: 34-44.

14. Tominaga Y, Uchida K, Haba T, Katayama A, Sato T,Hibi Y, Numano M, Tanaka Y, Inagaki H, Watanabe I, Hachisuka T, Takagi H.(2001) More than 1000 cases of total parathyroidectomy with forearm autograft for renal hyperparathyroidism. Am J Kidney Dis 38(Suppl 1): S168-S171.

15. Stanbury SW, Lumb GA, Nicholson WF. (1960) Elective subtotal parathyroidectomy for renal hyperparathyroidism. Lancet 1: 793-799.

16. Clark OH, Duh Q-Y (1997) Surgical approach to secondary hyperparathyroidism. In Textbook of Endocrine Surgery, WB Saunders: San Francisco, 403-409.

17. Gasparri G, Camandona M, Abbona GC, Papotti M, Jeantet A, Radice E Mullineris B, Dei Poli M (2001) Secondary and Tertiary hyperparathyroidism: causes of recurrent disease after 446 parathyroidectomies. Ann Surg 233: 65-69.

18. Kilgo M, Pirsch J, Warner T, Starling JR. (1998) Tertiary hyperparathyroidism after renal transplantation: surgical strategy. Surgery 124: 677-683.

19. Nichol PF, Starling JR, Mack E, Klovning JJ, Becker BN, Chen H. (2002) Long-term follow-up of patients with tertiary hyperparathyroidism treated by resection of a single or double adenoma. Ann Surg 235: 673-678.

20. Schwarz A, Rustien G, Merkel S, Radermacher J, Haller H. (2007) Decreased renal transplant function after parathyroidectomy. Nephrol Dial Transplant 22:584-591.

21. Schmid T, Muller P, Spelsberg F. (1997) Parathyroidectomy after renal transplantation: a retrospective analysis of long-term outcome. Nephrol Dial Transplant 12: 2393-2396.

22. Lee PP, Schiffmann L, Offermann G, Beige J (2004) Effects of parathyroidectomy on renal allograft survival. Kidney Blood Press Res 27: 191-196.

23. Susan CP, Rebecca SS, Herbert C. (2009) Secondary and Tertiary Hyperparathyroidism, State of the Art 
Surgical Management. Surg Clin N Am 89:1227-1239.

24. Evenepoel P, Claes K, Kuypers DR, Debruyne F, Vanrenterghem Y. (2007) Parathyroidectomy after successful kidney transplantation: a single centre study. Nephrol Dial Transplant 22: 1730-1737.

25. Drakopoulos S, Koukoulaki M, Apostolou T, Pistolas D, Balaska K, Gavriil S, Hadjiconstantinou V. (2009) Total parathyroidectomy without autotransplantation in dialysis patients and renal transplant recipients, longterm follow-up evaluation. Am J Surg 198: 178-183.

26. Milas M, Weber C. (2004) Near-total parathyroidectomy is beneficial for patients with secondary and tertiary hyperparathyroidism. Surgery 136: 1252-1260.

27. Punch J, Thompson N, Merion R. (1995) Subtotal parathyroidectomy in dialysis-dependent and post-renal transplant patients. A 25-year single-center experience. Arch Surg 130: 538-542.

28. Kebebew E, Duh Q, Clark O. (2004) Tertiary hyperparathyroidism: histologic patterns of disease and results of parathyroidectomy. Arch Surg 139: 974-977.

29. Garcia A, Mazuecos A, Garcia T, González P, Ceballos M, Rivero M. (2005) Effect of parathyroidectomy on renal graft function. Transplant Proc 37: 1459-1461.

30. Schlosser K, Endres N, Celik I, Fendrich V, Rothmund M, Fernandez ED. (2007) Surgical Treatment of Tertiary Hyperparathyroidism:The Choice of Procedure Matters! World J Surg 31: 1947-1953.

31. National Institute of Diabetes and Digestive and Kidney Diseases. (2004) US Renal Data System, USRDS 2004 annual data report: atlas of end-stage renal disease in the United States. Bethesda (MD): National Institutes of Health.

32. Meier-Kriesche HU, Steffen BJ, Hochberg AM, Gorgon RD, Liebman MN, Morris JA, Kaplan B. (2003) Mycophenolate mofetil versus azathioprine therapy is associated with a significant protection against long-term renal allograft function deterioration. Transplantation 75: 1341-1346. 